\title{
Dictyostelium discoideum Myosin: Isolation and Characterization of cDNAs Encoding the Regulatory Light Chain
}

\author{
SHERRIE R. TAFURI, ALICE M. RUSHFORTH, EDWARD R. KUCZMARSKI, AND REX L. CHISHOLM* \\ Department of Cell Biology and Anatomy, Northwestern University Medical School. 303 East Chicago Avenue. \\ Chicago, Illinois 606II
}

Received 17 January 1989/Accepted 28 March 1989

\begin{abstract}
Phosphorylation of the regulatory light chains (RMLC) of nonmuscle myosin can increase the actin-activated ATPase activity and filament formation. Little is known about these regulatory mechanisms and how the RMLC are involved in ATP hydrolysis. To better characterize the nonmuscle RMLC, we isolated cDNAs encoding the Dictyostelium RMLC. Using an antibody specific for the RMLC, we screened a $\lambda$ gt 11 expression library and obtained a 200-base-pair clone that encoded a portion of the RMLC. The remainder of the sequence was obtained from two clones identified by DNA hybridization, using the 200-base-pair cDNA. The composite RMLC cDNA was 645 nucleotides long. It contained 60 base pairs of $5^{\prime}$ untranslated, 483 bases of coding, and 102 base pairs of $3^{\prime}$ untranslated sequence. The amino acid sequence predicted an 18,300 -dalton protein that shares $42 \%$ amino acid identity with Dictyostelium calmodulin and $30 \%$ identity with the chicken skeletal myosin RMLC. This sequence contained three regions that were similar to the E-F hand calcium-binding domains found in calmodulin, troponin $C$, and other myosin light chains. A sequence similar to the phosphorylation sequence found in chicken gizzard and skeletal myosin light chains was found at the amino terminus. Genomic Southern blot analysis suggested that the Dictyostelium genome contains a single gene encoding the RMLC. Analysis of RMLC expression patterns during Dictyostelium development indicated that accumulation of this mRNA increases just before aggregation and again during culmination. This pattern is similar to that obtained for the Dictyostelium essential myosin light chain and suggests that expression of the two light chains is coordinated during development.
\end{abstract}

In nonmuscle cells, the actomyosin-based contractile system has been shown to be involved in many cellular functions, such as intracellular transport (52), cytokinesis $(19,45$. $48,54,55)$, phagocytosis (60), receptor capping (26), endocytosis and exocytosis (3), and pseudopodial and filipodial extension $(2,56)$. However, although the actomyosin contractile system is required for a number of nonmuscle cell phenomena, the functional structures and regulatory mechanisms of these systems are not well understood. Unlike muscle cell contractile systems, nonmuscle systems do not maintain a strict molecular organization such as that found in the sarcomere. The proteins involved are required for a multitude of phenomena and are reorganized accordingly. Using indirect immunofluorescence, Carboni and Condeelis (6) have demonstrated the rearrangement of actin, myosin, $\alpha$-actinin, and the 95 -kilodalton ( $\mathrm{kDa}$ ) protein during concavalin A-induced capping in Dictyostelium discoideum. Furthermore, using immunofluorescence, Yumura et al. (70) have demonstrated that myosin is present within the contractile ring of dividing Dictyostelium amoeba and in the cellular cortex of actively moving cells. Because of the dynamic nature of each component, elucidation of the structure and regulation of the individual components may aid in our understanding of the entire contractile mechanism.

Myosin monomers isolated from $D$. discoideum contain two 240,000-Da heavy chains (MHC), two 18,000-Da regulatory light chains (RMLC), and two 16.000-Da essential light chains (EMLC). The catalytic and actin-binding domains are localized to the globular head region of the MHC. Sequencing data reveal that these domains are highly homologous to the ATPase and actin-binding domains of muscle myosin (64). The tail region of the MHC is required for

\footnotetext{
* Corresponding author
}

assembly of the bipolar thick filament. Although this region is not homologous to similar regions in muscle myosin. the Dictyostelium MHC does contain amino acid patterns required for formation of the alpha-helical-coiled coil. In addition, the Dictyostelium MHC contains a 196-amino-acid repeat of charged amino acids that is believed to participate in filament formation. Phosphorylation of threonine residues within this repeat (61) decreases both the filament assembly and actin-activated $\mathrm{Mg}^{2+}$-ATPase activity of Dictyostelium myosin (33).

The RMLC are associated with the head region of the MHC. The EMLC is believed to function in the formation of the ATPase active site (41) and actin binding (46). As determined by cDNA sequencing, the Dictyostelium EMLC displays $30 \%$ amino acid sequence identity with the chicken skeletal muscle EMLC and contains three regions homologous to the consensus E-F hand calcium-binding domains common to most RMLC (8). The RMLC has been shown to modulate the enzymatic properties of myosin $(1,21,25,43$, $53,58)$. In smooth muscle and many nonmuscle systems, the $\mathrm{Ca}^{2+}$-dependent phosphorylation of the RMLC by myosin light-chain kinase increases the actin-activated ATPase activity of the myosin $(1,20,53,58)$. RMLC phosphorylation has been implicated in the regulation of platelet aggregation $(13,14)$, capping in lymphocytes (5), and smooth muscle tension (35). In D. discoideum, cyclic AMP (cAMP) stimulation induces RMLC phosphorylation (4): however, little is known about how phosphorylation affects myosin function in vivo.

The single-celled amoeba $D$. discoideum is an excellent system for the study of the regulation and function of nonmuscle cell myosins. Dictyostelium amoeba can be grown in large quantities, which has allowed the purification and characterization of many of the nonmuscle contractile 
components, including actin (59), myosin I (11), myosin II (9), and the myosin kinases $(20,32,38)$. In addition. throughout its life cycle, this organism exhibits several types of cell motility. This characteristic has enabled the analysis of events involved in motility, such as the regulation and organization of myosin within the cell. For example, using indirect immunofluorescence, Yumura and Fukui (69) have demonstrated that myosin is preferentially localized in the posterior cortex of the chemotaxing cell and that in the developmentally competent amoeba, myosin transiently relocalizes in response to cAMP stimulation. Berlot et al. (4) have been able to correlate this transient relocation of myosin with increases of heavy-and light-chain phosphorylation that are induced during cAMP stimulation.

Finally, application of molecular genetic techniques to $D$. discoideum has made it possible to disrupt expression and modify gene structure in vivo $(15,29,40,67)$. Disruption or modification of the $\mathrm{MHC}$ indicates that a functional $\mathrm{MHC}$ is required for cytokinesis and development (30), yet is not essential for cell locomotion or directed cell movement (29, $44,66)$. Similar molecular experiments will provide a powerful approach for studying the function of the RMLC in vivo.

\section{MATERIALS AND METHODS}

Isolation and screening of cDNA clones. The $\lambda \mathrm{gt} 11 \mathrm{cDNA}$ library used to isolate the MLC-R1A and RMLC-51 clones was derived from mRNA obtained from Dictyostelium cells developed for $12 \mathrm{~h}$ in the presence of cAMP (8). RMLC-k1 was obtained from a $\lambda$ gt 11 cDNA library constructed from 4-h developed cell mRNA (generously provided by Richard Kessin and his colleagues, Columbia University, New York, N.Y.). Àntibody screening as previously described (8) was used to isolate RMLC-1. Epitope selection was used to confirm the identity of RMLC-1 (65). To obtain the additional clones, plaque lifts of each library were probed with ${ }^{32}$ P-labeled DNA probes $(17,18)$. RMLC-2 was identified by using the ${ }^{32} \mathrm{P}$-labeled RMLC-1A insert, whereas RMLC-k1 was identified by a ${ }^{32} \mathrm{P}$-labeled restriction fragment of RMLC-2.

Subcloning and sequencing. Subcloning of the EcoRI inserts from RMLC-1, RMLC-2, and RMLC-k1 was done by standard methods (37). The resulting clones were sequenced on single- and double-stranded templates by chain termination sequencing techniques (51). DNA sequences of both strands were determined. DNA sequences were analyzed by using the Pustell/IBI (47) and University of Wisconsin Genetic Computer Group (16) software packages and the programs available through the Bionet National Resource.

Molecular hybridization techniques. For Southern blot analysis, restriction enzyme-digested Dictyostelium DNA was separated on agarose gels, depurinated in $0.25 \mathrm{M} \mathrm{HCl}$. and transferred to GeneScreen Plus (Dupont, NEN Research Products) in $0.4 \mathrm{M} \mathrm{NaOH}$ (49). Filters were prehybridized for at least $3 \mathrm{~h}$ at $65^{\circ} \mathrm{C}$ in DNA-DNA hybridization solution $(5 \times$ Denhardt solution, $6 \times$ SSC buffer [SSC is 0.15 $\mathrm{NaCl}$ plus 0.015 sodium citrate], $0.5 \%$ sodium dodecyl sulfate [SDS], $20 \mathrm{mM} \mathrm{NaPO}$ [pH 6.5], $10 \mu \mathrm{g}$ of calf thymus DNA per $\mathrm{ml}$ ). After prehybridization, the solution was replaced with fresh hybridization buffer containing $10^{6} \mathrm{cpm}$ of labeled probe per ml. Hybridization mixtures were incubated for 12 to $48 \mathrm{~h}$ at $65^{\circ} \mathrm{C}$. Probes were radiolabeled by random-primed synthesis $(17,18)$. After hybridization, filters were washed four times for $30 \mathrm{~min}$ in $250 \mathrm{ml}$ of $2 \times \mathrm{SSC}$ buffer $-0.1 \%$ SDS at $65^{\circ} \mathrm{C}$. Filters were exposed to Kodak

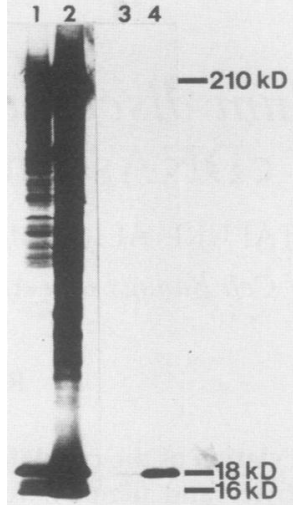

FIG. 1. Identification of the epitope encoded by the $\lambda \mathrm{gt} 11 \mathrm{cDNA}$ clone RMLC-1. Antibody specific for Dictyostelium myosin (NU3) was affinity purified by the epitope selection procedure, using the RMLC-1 CDNA clone. Both the purified antibody (lanes 3 and 4 ) and the original antiserum (lanes 1 and 2) were used to stain a whole-cell protein lysate (lanes 1 and 3 ) and purified myosin (lanes 2 and 4 ). The epitope-selected antibody recognized only the RMLC in both purified myosin and a whole-cell protein lysate.

X-Omat AR film (Eastman Kodak Co.) in the presence of Cronex Lightning-Plus intensifying screens (E. I. du Pont de Nemours \& Co.. Inc.).

For Northern (RNA) blots, RNA was transferred to nitrocellulose in $10 \times \mathrm{SSC}$ buffer and baked at $80^{\circ} \mathrm{C}$ for $2 \mathrm{~h}$ under vacuum. Hybridizations were performed in $50 \%$ deionized formamide-5 $\times$ SSC-50 $\mathrm{mM} \mathrm{NaPO}_{4}(\mathrm{pH} 6.5)-0.1 \%$ SDS-5 $\times$ Denhardt solution-10 $\mu \mathrm{g}$ of calf thymus DNA per ml at $37^{\circ} \mathrm{C}$. Washes were performed in $0.1 \times \mathrm{SSC}-0.1 \% \mathrm{SDS}$ at $50^{\circ} \mathrm{C}$.

\section{RESULTS}

Isolation of RMLC cDNAs. The $\lambda \mathrm{gt} 11$ library containing cDNAs representing poly $(A)^{+}$RNA isolated from $12-\mathrm{h}$ starved amoeba was screened with a $1: 100$ dilution of the anti-RMLC antibody NU3 (8). Positive plaques were picked and rescreened until plates contained only plaques reactive to NU3; 25 clones were isolated. Although NU3 reacted most strongly with the myosin light chains, some reactivity to the MHC was observed. To eliminate clones containing MHC sequences, the antibody-positive plaques were rescreened with NU3 that had been preabsorbed against isolated heavy chains (8). Four plaques reacted with the absorbed antibody and presumably contained myosin lightchain sequences. Epitope selection was used to distinguish between RMLC and EMLC clones $(8,65)$. The preabsorbed NU3 antibody was affinity purified against the fusion proteins produced by the individual clones. The resulting antibodies were reacted to nitrocellulose blots of purified Dictyostelium myosin. Antibody affinity purified against the proteins present in the RMLC-1 plaques reacted strongly with the 18-kDa light chain of purified myosin (Fig. 1, lane 4) as well as a single $18-\mathrm{kDa}$ band in a whole-cell lysate (lane 3 ). Slight cross-reactivity against the 16-kDa light chain was also observed. Perhaps this cross-reactivity resulted from regions of structural similarity between the essential and regulatory light chains.

To examine the nature of the NU3-reactive protein being produced by bacteria infected with $\lambda \mathrm{gt} 11$ containing the RMLC-1 cDNA, Escherichia coli Y1089 (68) was lysogenized by bacteriophage carrying the RMLC-1 cDNA. After temperature induction of the phage and isopropyl- $\beta$ - $D$-thio- 


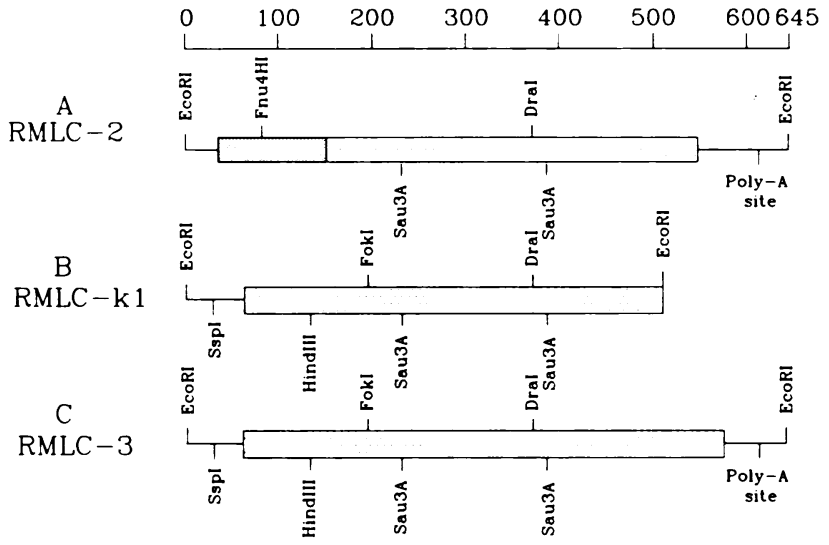

FIG. 2. Partial restriction map of RMLC cDNA clones. Shown are cDNA inserts isolated from RMLC-2 (A), RMLC-k1 (B), and RMLC-3 (C). Lines represent untranslated regions: boxed regions represent coding sequences. The densely stippled area in the RMLC-2 sequence represents the position at which there is a shift in the reading frame.

galactopyranoside (IPTG) induction of $\beta$-galactosidase, cells were harvested, suspended in SDS sample buffer, and analyzed by SDS-polyacrylamide gel electrophoresis. $\beta$-Galactosidase was absent from RMLC-1 cell extracts; however, a larger protein that was not present in cells infected with unmodified $\lambda \mathrm{gt} 11$ was identified. Immunoblotting showed that the new protein reacted with the NU3 antibody, confirming that the RMLC-1 phage was indeed expressing a $\beta$-galactosidase-RMLC fusion protein.

EcoRI restriction digestion of purified RMLC-1 DNA revealed the presence of two EcoRI fragments with lengths of 140 (RMLC-1A) and 194 (RMLC-1B) nucleotides. This finding suggested that either an endogenous EcoRI site within the cDNA was protected during the digests required for construction of the library. or that two unrelated fragments were ligated to form a single clone. Double-stranded sequencing of the phage DNA showed that RMLC-1A was linked in frame to the $\beta$-galactosidase gene, suggesting that this fragment contained RMLC sequences. To provide additional evidence supporting this idea, ${ }^{32} \mathrm{P}$-labeled probes were made from each fragment and used to probe a blot of RNA isolated from vegetative cells. Only RMLC-1A reacted with an mRNA of a size required to synthesize the $18-\mathrm{kDa}$ RMLC. The RMLC-1B fragment reacted with an mRNA of only about 400 nucleotides, far too short to encode an $18-\mathrm{kDa}$ polypeptide. Because the two fragments reacted with different mRNAs, the two EcoRI inserts most likely represented unrelated cDNAs. On the basis of these results, we concluded that the $1 \mathrm{~A}$ fragment represented an RMLC cDNA.

To obtain a cDNA containing the entire coding sequence for the RMLC, the RMLC-1A fragment was used to rescreen the $\lambda$ gt 11 cDNA library. Several positive clones were isolated. A restriction digest with EcoRI showed that the clone designated RMLC-2 contained a 643-base-pair insert. The insert from RMLC-2 was subcloned into M13 and Bluescript vectors (Stratagene) and sequenced. Figure $2 \mathrm{~A}$ shows a partial restriction map of the RMLC-2 cDNA. Although the sequence obtained appeared to contain a typical Dictyostelium translation start sequence and methionine, it did not contain a single open reading frame. One reading frame initiated at the suspected start site and continued for 150 bases. The second open reading frame began at base 90 and terminated at the termination codon found at nucleotide 544 . The sequence homologous to RMLC-1A resided within the second open reading frame. Comparison of the predicted amino acid sequence with known RMLC protein sequences demonstrated that the sequence encoded by the $3^{\prime}$ portion of the mRNA was similar to that of chicken skeletal RMLC. The 5' 150 bases showed no homology to any known myosin sequence. To determine whether the 5 ' portion of sequence was related to the RMLC, a probe containing the 5' region of the RMLC was synthesized by a primer extension reaction (37) and hybridized to a blot of restriction enzyme-cut RMLC-2. The primer used for the extension was a synthetic oligonucleotide complementary to the region surrounding the FokI site of RMLC-2. This probe failed to react with the first 100 bases of RMLC-2, suggesting that this sequence did not code for the RMLC. Presumably, this $5^{\prime}$ sequence represents the ligation of two individual cDNAs before addition of linker during construction of the library.

To obtain a clone containing the authentic $5^{\prime}$ end of the RMLC cDNA, the 140-base-pair internal Sau3A restriction fragment from the 3' coding region of RMLC-2 was labeled and used to probe a $\lambda \mathrm{gt} 11$ library containing cDNAs representing mRNA isolated from Dictyostelium cells developed for $4 \mathrm{~h}$ (36). A clone, RMLC-k1, containing a 510-base-pair EcoRI insert was isolated. A partial restriction map of RMLC-k1 is presented in Fig. 2B. RMLC-k1 contained an $\mathrm{A}+\mathrm{T}$-rich 5' untranslated sequence, a typical Dictyostelium translation start sequence, initiator methionine, and $94 \%$ of the RMLC-coding sequence. RMLC-k1 did not contain the last 135 nucleotides of $3^{\prime}$ sequence; however, the RMLC-k1 sequence from bases 150 to 510 was identical to the same regions in RMLC-2. As suspected, the 5' 150 base pairs was not homologous to the corresponding region of RMLC-2. A complete cDNA was constructed by using the appropriate FokI-EcoRI restriction fragments from RMLC-2 and RMLC$\mathrm{k} 1$ and was designated RMLC-3. A partial restriction map of RMLC-3 is presented in Fig. 2C. Figure 3 shows the complete DNA sequence for RMLC and the predicted amino acid sequence of the encoded polypeptide. The sequence contains a 60-nucleotide untranslated leader sequence, a typical A-rich translational start sequence, and initiator methionine. The open reading frame encodes 161 amino acids which constitute a polypeptide with a predicted molecular weight of 18,303 . The predicted isoelectric point for this peptide is 5.9 , consistent with that observed for the Dictyostelium RMLC polypeptides. In addition, the cDNA contains about $1003^{\prime}$ untranslated nucleotides which contain a eukaryotic consensus polyadenylation sequence (AATAAA) 75 nucleotides downstream from the translation termination signal.

The Dictyostelium RMLC displayed amino acid homology with calmodulin, troponin $\mathrm{C}$, and other regulatory light chains. The results of a comparison of the amino acid sequences of Dictyostelium calmodulin and the RMLC are shown in Fig. 4. The RMLC showed $42 \%$ sequence identity to Dictyostelium calmodulin. The RMLC calcium-binding domains corresponded to domains 1 to 3 in the calmodulin sequence. Significant sequence homology was also evident outside the binding domains, particularly in the region preceding domain 1 . Figure 5 shows dot matrix sequence homology comparisons between the Dictyostelium RMLC and the chicken cardiac $2 b$, rabbit skeletal muscle, and smooth muscle RMLC. Sequence homology was spread evenly throughout the peptides and included the regions containing calcium-binding and phosphorylation sites. The 
10 30

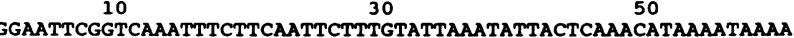
ATGGCCTCAACCAAAAGAagATTAAACAGAGAAGAATCATCTGTAGTTTTAGGTGAagAa MetAlaSerThrLysArgArgLeuAsnArgGlugluSerSerValValLeuGlyGluglu 130 150 170

CAAGTTGCTGAATTAAAAGAAGTTTTGAACTCTTTGATAAAGATAGAACTGGTTTCATT GInVaIAl aGluLeuLysGluAla PheGluLeuPheAspLysAspArgThrGlyPheIle 190 210

AAAAAGGATGCCTTAAAAACCACCTGTAAACAATTTGGTGTTTTTGTTATGGAAGATCAA LysLysAspAlaLeuLysThrThrCysLysGInPheGlyValPheValMetGluAspGin

$$
250
$$

270

290

TTAGATGCCATGTTTGCTGAAGCTGATACCACCAAATCTGGTGCTATTGGTTTCCCAGAA LeuAsPAl aMetPhEA IGIUAl aAspThrThrLysSerGI YAlaIl eGlyPheProGlu

310

330

350

TTTATGTCAATGATGTCCCGTCGTATGAAACAAACTTCAAATGAACAAATTTTAATGAAC PheMetSerMetMetSerArgArgMetLysGinThrSerAsnGluGinIleLeuMetAsn

$\begin{array}{cc}370 & 390 \\ \text { GCTTTTAAAACTTTTGATCCAGAAGGTATGGTTACATCTTAACAAAAGTTTATCTAAA }\end{array}$ Ala PheLYSThrPheAspPrOGIUGIYAsnGlyTyrIleLeuThrLYsAspLeuSerLys

$\begin{array}{cc}430 & 450 \\ \text { GCCTTAACAATTTGGGTGATAAATAACTGAagCAGAGTTACAAGAATGTTATCAATT }\end{array}$ Al a LeuThrThrLeuGlyAspLysLeuThrGluAlagluLeuGInGluLeuLeuSerIle

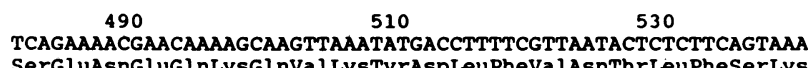
SerGluAsnGluGInLysGInValLysTyrAspLeuPheValAsnThrLeuPheSerLys

$$
550
$$

570

590

AAATAAAGTGATTATTAAATAGTGGAAAAAAAAAAAAAAGTATGTTAAAAACGTTTAGGg LyS

610
AGAAGAATTAAATAAAAAAAAAAAAAATATATAAAAAAAACAA

610
AGAAGAATTAAATAAAAAAAAAAAAAATATATAAAAAAAACAA

FIG. 3. Nucleotide and amino acid sequences of RMLC-3 cDNA. The predicted amino acid sequence is depicted below the corresponding nucleotide codons.

most divergent portions were located at the carboxyl terminus.

Southern blot analysis of the RMLC gene(s). To determine the number of RMLC genes in the Dictyostelium genome, the RMLC-3 cDNA was labeled and used to probe Dictyostelium DNA that had been digested with variety of restriction enzymes (Fig. 6). A single restriction fragment containing the RMLC was detected in several digests produced by enzymes that do not cut within the cDNA. This finding suggests that there is a single copy of the RMLC gene within the genome. Further restriction analysis has indicated that the gene contains at least two introns (data not shown). We are currently isolating genomic clones to determine the organization of the RMLC gene.

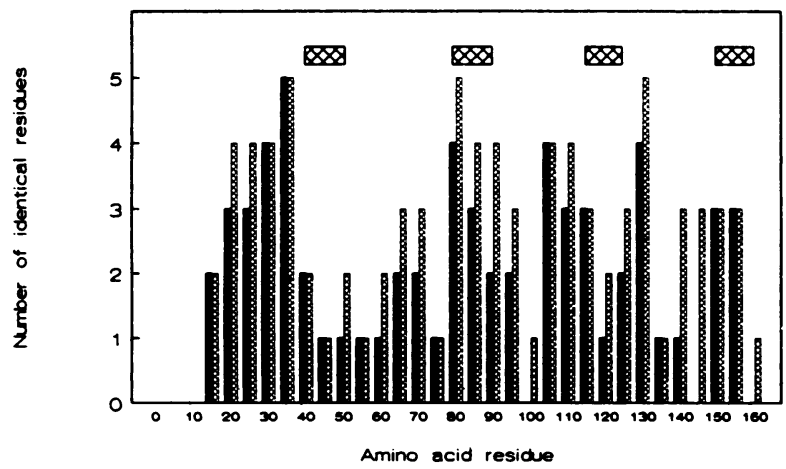

FIG. 4. Histogram representing the sequence conservation between Dictyostelium calmodulin and the Dictyostelium RMLC. Each bar represents the number of identical residues present within a five-amino-acid window. Filled bars represent absolute sequence homology; sequence identities (hatched bars) include conservative amino acid changes. Hatched boxes at the top indicate the positions of the $\mathrm{Ca}^{2+}$-binding domains in Dictyostelium calmodulin.

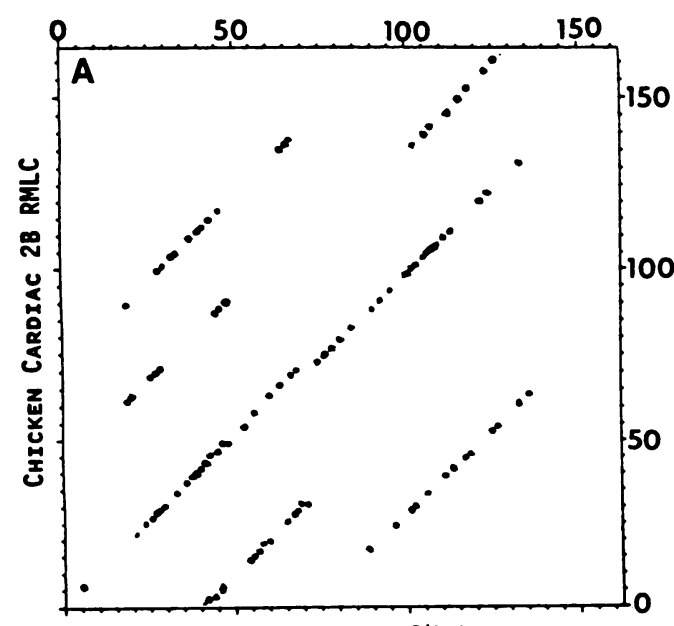

Dictrostelium RMLC
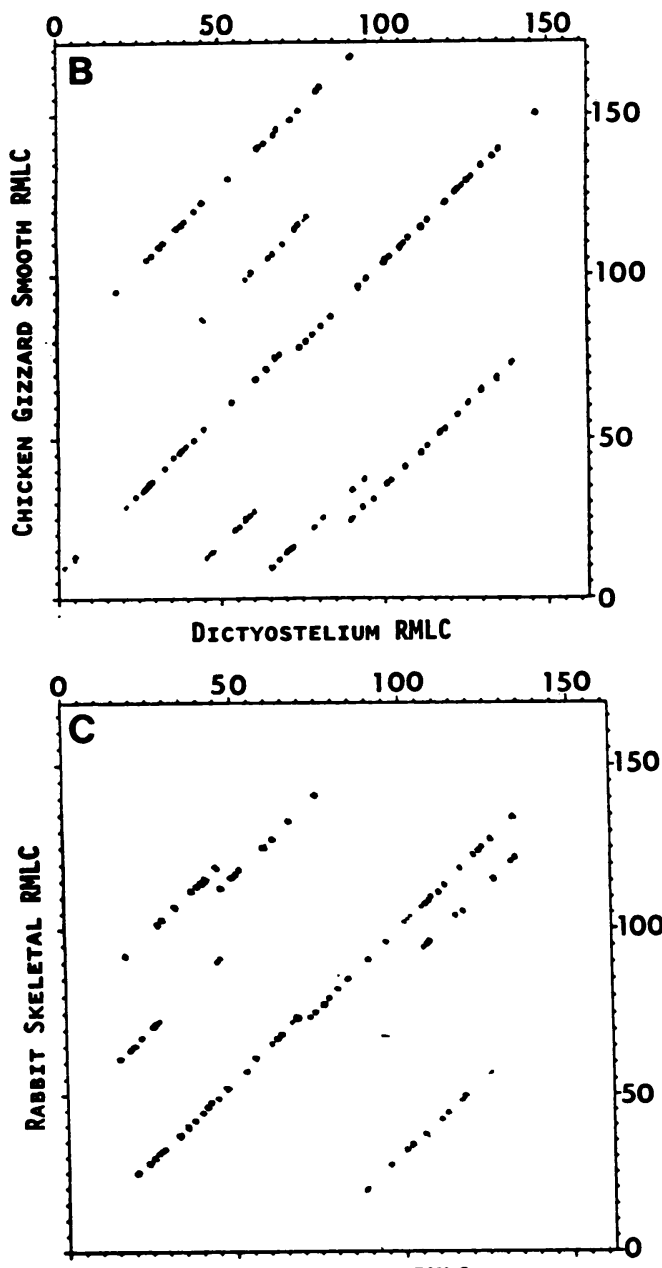

Dictrostelium RMLC

FIG. 5. Dot matrix plot showing the extents and locations of homologous regions between the amino acid sequences of the Dictyostelium RMLC and the chicken cardiac 2b (A), chicken gizzard smooth muscle (B), and rabbit skeletal (C) RMLC. Each dot represents identity of at least 8 of 30 amino acids. 


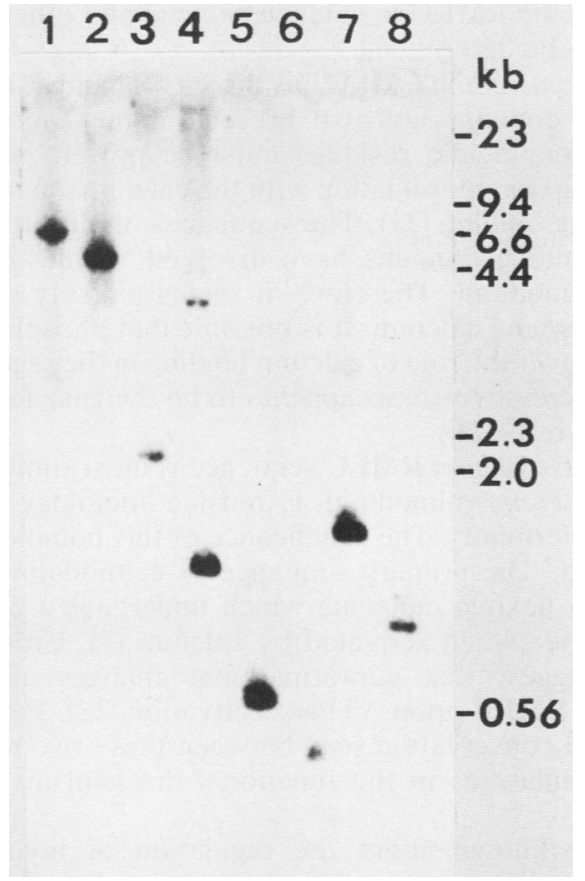

FIG. 6. Southern blot analysis of Dictyostelium genomic DNA. Autoradiograph of restriction enzyme-cut genomic Dictvostelium DNA that has been probed with ${ }^{32}$ P-labeled RMLC-3 cDNA. The single bands seen in several of the digests indicate the presence of a single RMLC gene within the Dictyostelium genome. Lanes: 1. ClaI: 2. EcoRI; 3, Fokl: 4, HindIII: 5, Hinfl: 6. Hphl: 7. Rsal: 8. Sspl. kb. Kilobases.

Developmental regulation of the RMLC mRNA. The rate of cell movement in $D$. discoideum increases during the aggregative stages of development (62). To determine whether the increases in cell motility are associated with increased levels of RMLC mRNA, we examined the expression of RMLC mRNA throughout development by Northern blot analysis. Total cellular RNA was prepared from cells harvested at 4-h intervals during development. Equal amounts of RNA were loaded in each lane of the gel. Equivalent RNA loading was confirmed by ethidium bromide staining and comparison of the amounts of $27 \mathrm{~S}$ and $17 \mathrm{~S}$ rRNAs. Blots were probed with the cDNA isolated from RMLC-3. A single 800-base-pair mRNA was detected (Fig. 7A). The size of the detected mRNA was sufficient to encode a polypeptide of $18 \mathrm{kDa}$ and was similar to that seen in other systems. Densitometry was used to determine the level of mRNA present within each sample. After $4 \mathrm{~h}$ of development, the levels RMLC mRNA were fivefold higher than in vegetative cells (Fig. 7B), suggesting that aggregation may indeed be associated with increases of RMLC synthesis. At 8 and $12 \mathrm{~h}$, levels of RMLC mRNA returned to values similar to those seen in vegetative cells. A 2.6-fold accumulation occurred at 16 and $20 \mathrm{~h}$. This period corresponds to the point in development when the stalk and fruiting body are forming. This pattern of expression was similar to that we previously reported for the EMLC (8).

\section{DISCUSSION}

In this report, we describe the isolation and characterization of cDNAs encoding the RMLC from $D$. discoideum. The RMLC-3 cDNA encoding the RMLC is 645 nucleotides
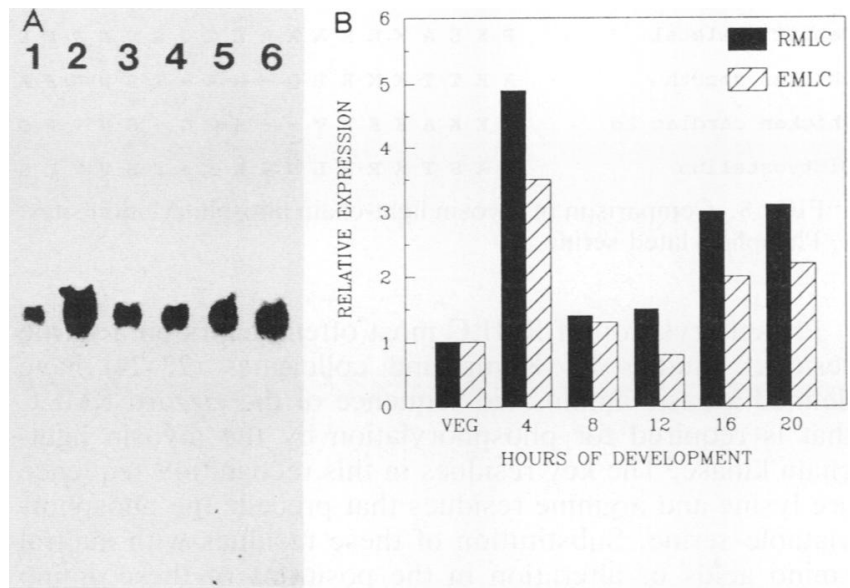

FIG. 7. Developmental regulation of the RMLC mRNA. (A) Dictyostelium total RNA was isolated from cells at different stages during development and probed with ${ }^{32} \mathrm{P}$-labeled RMLC-2. Lanes: 1. vegetative cell RNA: 2 through 6 , RNA isolated from cells after 4 (lane 2), 8 (lane 3), 12 (lane 4). 16 (lane 5), and 20 (lane 6) h of development. bp. Base pairs. (B) Histogram showing levels of RMLC (I) and EMLC (E) mRNAs. Densitometry of the autoradiograph indicates that synthesis of RMLC-2 mRNA increased fivefold after $4 \mathrm{~h}$ of development, returned to vegetative levels by $8 \mathrm{~h}$. and again increased slightly after $12 \mathrm{~h}$.

long and contains a single open reading frame initiating at a methionine codon positioned at nucleotide 60 . Similar to other Dictyostelium mRNAs, including that for the EMLC (8), and MHC (64), and actin (28) genes, the 5' untranslated sequence is $\mathrm{A}+\mathrm{T}$ rich and the RMLC translation initiation codon is preceded by an A stretch. A consensus polyadenylation site at nucleotide 610 follows the TAA translation termination codon generally found in D. discoideum (27). The cDNA encodes a protein of 161 amino acids with a predicted molecular mass of 18,300 Da. This value agrees with the molecular mass determined by SDS-polyacrylamide gel electrophoresis (9). The calculated pI for this protein of 5.9 is in agreement with the values obtained from isoelectric focusing studies (unpublished results).

RMLC cDNAs have been cloned from skeletal, smooth, and cardiac muscle cells from a variety of species. Sequence analysis indicates that the RMLC from a given muscle type are highly homologous between species, whereas those from different muscle systems within the same organism show much less homology. For example, there is $83 \%$ homology between rat and chicken cardiac RMLC versus $67 \%$ homology between rat cardiac and skeletal RMLC (34). Perhaps these sequence variations are responsible for specific functional differences. The Dictyostelium RMLC amino acid sequence is $42 \%$ homologous to Dictyostelium calmodulin, $34 \%$ homologous to the chicken cardiac 2b RMLC, $32 \%$ homologous to the smooth muscle RMLC, and 30\% homologous to the rabbit skeletal RMLC. The sequence identity among the RMLC is spread evenly throughout the peptides and includes the potential calcium-binding domains and the phosphorylation sites. Presumably, a portion of the remaining regions is responsible for $\mathrm{MHC}$ binding. The sequences diverge significantly in the carboxy-terminal portions of the peptides. Moreover, the amino acid sequence of the Dictyostelium EMLC carboxyl terminus also diverges from that of other EMLC. It is not known whether these sequence variations define functional differences between muscle and nonmuscle RMLC. 


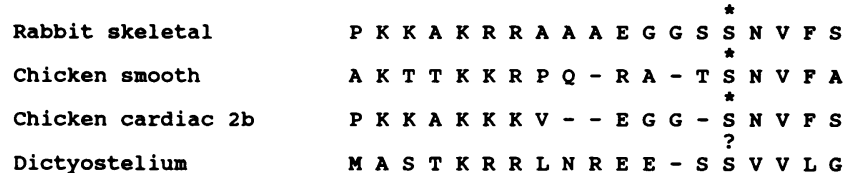

Dictyostelium

FIG. 8. Comparison of myosin light-chain phosphorylation sites. *, Phosphorylated serine.

Phosphorylation of RMLC most often occurs on a serine residue. Studies by Kemp and colleagues (22-24) have defined a basic amino acid sequence of the gizzard RMLC that is required for phosphorylation by the myosin lightchain kinase. The key residues in this recognition sequence are lysine and arginine residues that precede the phosphorylatable serine. Substitution of these residues with neutral amino acids or alteration in the positions of these amino acids disrupts or alters phosphorylation. In addition, the four amino acids on the carboxyl-terminal side of the phosphorylation site have a strong influence on the reaction kinetics (42). Removal of the valine or phenyalanine residues in this sequence decreases the $V_{\max }$ of the phosphorylation reaction. Sequence comparisons have revealed that all phosphorylatable RMLC contain similar amino acid domains. Similar basic amino acid sequences are used as phosphorylation recognition sequences by a variety of cellular kinases (22).

The Dictyostelium RMLC is phosphorylated on a serine residue (4). Preceding serine-13 and serine-14 in the Dictyostelium RMLC are several arginine and lysine residues. These residues are positioned similarly to those in the gizzard RMLC (Fig. 8). However, the carboxyl-terminal sequence following the putative phospho residues diverges significantly from that seen in other RMLC. This is unusual, since this sequence is absolutely conserved in all reported muscle RMLC sequences. Studies have indicated that the Dictyostelium myosin light-chain kinase is highly specific and will not phosphorylate myosins isolated from rabbit skeletal and cardiac muscle, turkey smooth muscle, platelet. or Acanthamoeba cells. Moreover, gizzard myosin lightchain kinase does not phosphorylate the Dictyostelium RMLC (20; S. R. Tafuri and E. R. Kuczmarski. J. Cell Biol. 101:160a, 1985). The variations seen in sequence surrounding the phosphorylation site may explain the specificities of these enzymes. Further analysis is required to determine which serine is the phosphorylated residue.

The $\mathrm{Ca}^{2+}$-binding regions of the RMLC demonstrate the highly conserved E-F hand structure common to many calcium-binding proteins, including calmodulin and troponin $C$ (31). This structure is found in the essential and regulatory light chains of most myosins studied (10). In several systems, such as scallop and chicken skeletal muscle. evidence suggests that at least one of these domains is functional. The binding of $\mathrm{Ca}^{2+}$ to the head region of scallop myosin is responsible for the stimulation of the actin-activated myosin ATPase activity (25). The scallop RMLC is not phosphorylated. Loss of RMLC from scallop myosin results in desensitization to calcium regulation. RMLC from other sources can be reassociated the densensitized myosin and tested to see whether they can restore calcium sensitivity to scallop myosin. The chicken skeletal RMLC prevents calcium activation of scallop myosin activity. However, mutation of calcium-binding domain I of the chicken skeletal RMLC relieves this inhibition (50). This finding suggests that the chicken RMLC does actively bind calcium and that this binding regulates the interaction between actin and myosin in scallop hybrids. At present, the function of calcium

binding by the RMLC in chicken skeletal and other systems remains to be determined.

The Dictyostelium EMLC has three E-F hand domains (8), and three domains are also present in the Dictyostelium RMLC. Four acidic residues must be present within the binding loop for coordination with the calcium ion in order to have strong binding (31). The sequences of all three RMLC calcium-binding domains have diverged significantly from that of calmodulin. Therefore, it seems unlikely that these light chains bind calcium. It is possible that phosphorylation has taken over the role of calcium binding in the regulation of Dictyostelium myosin, as appears to be the case for smooth muscle myosin (25).

The Dictyostelium RMLC sequence is most similar to that of Dictyostelium calmodulin. Extensive homology occurs at the amino terminus. The significance of this homology is not understood. The primary sequence of calmodulin suggests that it is a flexible molecule which undergoes a conformational change when activated by calcium (7). Cross-linking studies suggest that conformational changes also occur within the RMLC upon ATPase activation (12). Perhaps the amino acid conservation seen between these two molecules reflects similarities in the functional mechanisms of these proteins.

Little is known about the regulation of myosin gene expression. Questions still to be answered include those concerning how myosin subunit expression is coordinated, how myosin expression is synchronized with that of other contractile proteins, and which cellular events require myosin synthesis. During Dictyostelium development, synthesis of RMLC mRNAs increases just before aggregation and again a few hours before culmination. This pattern of expression mimics that observed for EMLC, suggesting that synthesis of the light chains (and presumably the heavy chain) is coordinated and possibly regulated by similar mechanisms. Furthermore, the pattern of actin transcription is similar to that of the light chain. Therefore, mechanisms that regulate myosin expression may also coordinate the expression of a variety of contractile proteins within the cell. It will be of interest to determine how the structural elements controlling the regulation of the contractile components compare.

Since RMLC synthesis appears to occur during aggregation and culmination, it will be interesting to determine the phenotypes of cells lacking the RMLC. MHC expression mutants are capable of cAMP-directed movement and can aggregate; however, cell movement is much slower than in wild-type cells (66). It is possible that RMLC mutants will have similar motility defects. Alternatively, since light chains are not required for functional ATPase in several systems $(39,57,63)$, it is quite possible that a different phenotype will arise. Now that the Dictyostelium RMLC has been cloned and sequenced, it can be used in transformation studies to determine the function of the RMLC in vivo and to define the domains within the RMLC that are important for RMLC and myosin function.

\section{ACKNOWLEDGMENTS}

We thank Richard Kessin and his colleagues for generously allowing us to screen their cDNA library. We also thank the other members of the laboratory for helpful discussions.

This work was supported by Public Health Service grants GM39264 and GM34811 to R.L.C. from the National Institutes of Health.

\section{LITERATURE CITED}

1. Adelstein, R. S., and M. A. Conti. 1975. Phosphorylation of platelet myosin increases actin-activated myosin ATPase activ- 
ity. Nature (London) 256:597-598.

2. Albrecht-Buehler, G. 1976. The function of filipodia in spreading 3T3 mouse fibroblasts, p. 247-264. In R. Goldman. T. Pollard. and J. Rosenbaum (ed.). Cell motility. Cold Spring Harbor Laboratory, Cold Spring Harbor, N.Y.

3. Allison, A. C. 1976. The role of contractile systems in endocytosis and exocytosis, p. 333-347. In S. V. Perry, A. Margreth. and R. S. Adelstein (ed.), Contractile systems of non-muscle tissues. North-Holland Publishing Co.. Amsterdam.

4. Berlot, C. H., P. N. Devreotes, and J. A. Spudich. 1987. Chemoattractant-elicited increases in Dictyostelium myosin phosphorylation are due to changes in myosin localization and increases in kinase activity. J. Biol. Chem. 262:3918-3926.

5. Bourguignon, L. Y. W., M. L. Nagpal, and Y.-C. Hsing. 1981. Phosphorylation of myosin light chains during capping of mouse T-lymphoma cells. J. Cell Biol. 91:889-894.

6. Carboni, J. M., and J. S. Condeelis. 1985. Ligand-induced changes in the location of actin. myosin. $95 \mathrm{k}$ protein, and $120 \mathrm{~K}$ protein in amoebae of Dictyostelium discoideum. J. Cell Biol. 100:1884-1893.

7. Cheung, W. Y. 1980. Calmodulin plays a pivotal role in cellular regulation. Science 207:19-27.

8. Chisholm, R. L., A. M. Rushforth, R. S. Pollenz, E. R. Kuczmarski, and S. R. Tafuri. 1988. Dictyostelium discoideum myosin: isolation and characterization of cDNAs encoding the essential light chain. Mol. Cell. Biol. 8:794-810.

9. Clark, M., and J. A. Spudich. 1974. Biochemical and structural studies of actomyosin-like proteins from non-muscle cells. J. Mol. Biol. 86:209-222.

10. Collins, J. H. 1976. Homology of myosin DTNB light chain with alkali light chains, troponin $\mathrm{C}$ and parvalbumin. Nature (London) 259:699-700.

11. Cote, G. P., J. P. Albanesi, I. Ueno, J. A. Hammer III, and E. D. Korn. 1985. Purification from Dictyostelium discoidium of a low-molecular-weight myosin that resembles myosin I from Acanthamoeba castellanii. J. Biol. Chem. 260:4543-4546.

12. Craig, R., R. Smith, and J. Kendrick-Jones. 1983. Light chain phosphorylation controls the conformation of vertebrate nonmuscle and smooth muscle myosin molecules. Nature (London) 302:436-439.

13. Daniel, J. L., I. R. Molish, and H. Holmsen. 1981. Myosin phosphorylation in intact platelets. J. Biol. Chem. 256:7510 7514.

14. Daniel, J. L., I. R. Molish, M. Rigmaiden, and G. Stewart. 1984. Evidence for a role of myosin phosphorylation in the initiation of the platelet shape change response. J. Biol. Chem. 259: 9826-9831.

15. De Lozanne, A., and J. A. Spudich. 1987. Disruption of the Dictyostelium myosin heavy chain gene by homologous recombination. Science 236:1086-1091.

16. Devereux, J., P. Haeberti, and O. Smithes. 1984. A comprehensive set of sequence analysis programs for the Vax. Nucleic Acids Res. 12:387-395.

17. Feinberg, A., and B. Vogelstein. 1983. A technique for radiolabeling DNA restriction endonuclease fragments to high specific activity. Anal. Biochem. 132:6-13.

18. Feinberg, A., and B. Vogelstein. 1984. A technique for radiolabeling DNA restriction endonuclease fragments to high specific activity. Anal. Biochem. 137:266-267.

19. Fujiwara, K., and T. D. Pollard. 1976. Fluorescent antibody localization of myosin in the cytoplasm. cleavage furrow. and mitotic spindle of human cells. J. Cell Biol. 71:848-875.

20. Griffith, L. M., S. M. Downs, and J. A. Spudich. 1987. Myosin light chain kinase and myosin light chain phosphatase from Dictyostelium: effects of reversible phosphorylation on myosin structure and function. J. Cell Biol. 104:1309-1323.

21. Harrington, W. F., and E. Rogers. 1984. Myosin. Annu. Rev. Biochem. 53:35-73.

22. Kemp, B. E., and R. B. Pearson. 1985. Spatial requirements for location of basic residues in peptide substrates for smooth muscle myosin light chain kinase. J. Biol. Chem. 260:3355-3359.

23. Kemp, B. E., R. B. Pearson, and C. House. 1982. Phosphorylation of a synthetic heptapeptide by smooth muscle myosin light chain kinase. J. Biol. Chem. 257:13349-13353.

24. Kemp, B. E., R. B. Pearson, and C. House. 1983. Role of basic residues in the phosphorylation of synthetic peptides by myosin light chain kinase. Proc. Natl. Acad. Sci. USA 80:7471-7475.

25. Kendrick-Jones, J., and J. M. Scholey. 1981. Myosin-linked regulatory systems. J. Muscle Res. Cell Motil. 2:347-372.

26. Kerrick, W. G., and L. W. Bourguignon. 1984. Regulation of receptor capping in mouse lymphoma $T$ cells by a $\mathrm{Ca}^{+2}$ activated myosin light chain kinase. Proc. Natl. Acad. Sci. USA 81:165-169.

27. Kimmel, A. R., and R. A. Firtel. 1982. The organization and expression of the Dictyostelium genome, p. 234-324. In W. F. Loomis (ed.). The development of Dictyostelium discoidium. Academic Press. Inc.. New York.

28. Kimmel, A. R., and R. A. Firtel. 1983. Sequence organization in Dictyostelium: unique structure at the $5^{\prime}$ ends of protein coding genes. Nucleic Acids Res. 11:541-552.

29. Knecht, D. A., and W. F. Loomis. 1987. Anti-sense RNA inactivation of myosin heavy chain gene expression in Dictyostelium discoideum. Science 236:1081-1086.

30. Knecht, D. A., and W. F. Loomis. 1988. Developmental consequences of the lack of myosin heavy chain in Dictyostelium discoidium. Dev. Biol. 128:178-184.

31. Kretsinger, R. H. 1980. Structure and evolution of calcium modulated proteins. Crit. Rev. Biochem. 8:119-174.

32. Kuczmarski, E. R. 1986. Partial purification of two myosin heavy chain kinases from Dictyostelium discoidium. J. Muscle Res. Cell Motil. 7:501-509.

33. Kuczmarski, E. R., and J. A. Spudich. 1980. Regulation of myosin self-assembly: phosphorylation of Dictyostelium heavy chain inhibits formation of thick filaments. Proc. Natl. Acad. Sci. USA 77:7292-7296.

34. Kumar, C. C., L. Cribbs, P. Delaney, K. R. Chien, and M. A. Q. Siddiqui. 1986. Heart myosin light chain 2 gene. J. Biol. Chem. 261:2866-2872.

35. Kuznicki, J., and B. Barylko. 1988. Phosphorylation of myosin in smooth muscle and non-muscle cells: in vitro and in vivo effects. Int. J. Biochem. 20:559-568.

36. Lacombe, M. L., G. J. Podgorski, J. Franke, and R. H. Kessin. 1986. Molecular cloning and developmental expression of the cyclic nucleotide phosphodiesterase gene from Dictyostelium discoideum. J. Biol. Chem. 261:16811-16817.

37. Maniatis, T., E. F. Fritsch, and J. Sambrook. 1980. Molecular cloning: a laboratory manual. Cold Spring Harbor Laboratory, Cold Spring Harbor. N.Y.

38. Maruta, H., W. Bates, P. Dieter, D. Marme, and G. Gerisch. 1983. Myosin heavy chain kinase inactivated by $\mathrm{Ca}^{+2} / \mathrm{calmod}^{-}$ ulin from aggregating cells of Dictyostelium discoidium. EMBO J. 2:535-542.

39. Maruta, H., H. Gadasi, J. H. Collins, and E. D. Korn. 1978. The isolated heavy chain of an Acanthamoeha myosin contains full enzymatic activity. J. Biol. Chem. 253:6297-6300.

40. Nellen, W., C. Silan, and R. A. Firtel. 1984. DNA-mediated transformation in Dictyostelium discoideum: regulated expression of an actin gene fusion. Mol. Cell. Biol. 4:2890-2898.

41. Okomoto, Y., T. Sekine, J. Grammer, and R. G. Yount. 1986. The essential light chains constitute part of the active site of smooth muscle myosin. Nature (London) 324:78-80.

42. Pearson, R. B., L. Y. Misconi, and B. E. Kemp. 1986. Smooth muscle myosin kinase requires residues on the $\mathrm{COOH}$-terminal side of the phosphorylation site. J. Biol. Chem. 261:25-27.

43. Persechini, A., and D. J. Hartshorne. 1981. Phosphorylation of smooth muscle myosin: evidence for cooperativity between the myosin heads. Science 213:1383-1385.

44. Peters, D. J. M., D. A. Knecht, W. F. Loomis, A. De Lozanne, J. A. Spudich, and P. J. M. Van Hastert. 1988. Signal transduction. chemotaxis, and cell aggregation in Dictyostelium discoidium cells without myosin heavy chain. Dev. Biol. 128:158-163.

45. Pollard, T. D., and K. Fujiwara. 1976. Participation of contractile proteins in cytoplasmic structure and cell division. p. 23-28. In S. V. Perry. A. Margreth. and R. S. Adelstein (ed.). Contractile systems in non-muscle tissues. North-Holland Publishing Co.. Amsterdam. 
46. Prince, H. P., H. R. Trayer, G. D. Henry, I. P. Trayer, and D. C. Dalgarno. 1981. Proton nuclear-magnetic-resonance spectroscopy of myosin subfragment I isoenzymes. Eur. J. Biochem. 121:213-219.

47. Pustell, J., and F. C. Kafatos. 1984. A convenient and adaptable package of computer programs for DNA and protein sequence management, analysis and homology determination. Nucleic Acids Res. 12:643-655.

48. Rappaport, R. 1967. Cell division: direct measurement of maximum tension exerted by furrow of echinoderm eggs. Science 156:1241-1242.

49. Reed, K. C., and D. A. Mann. 1985. Rapid transfer of DNA from agarose gels to nylon membranes. Nucleic Acids Res. 13: 7202-7221.

50. Reinach, F. C., K. Nagai, and J. Kendrick-Jones. Site-directed mutagenesis of the regulatory light-chain $\mathrm{Ca}^{+2} / \mathrm{Mg}^{+2}$ binding site and its role in hybrid myosins. Nature (London) 322:80-83.

51. Sanger, F., S. Nicklen, and A. R. Coulson. 1977. DNA sequencing with chain-terminating inhibitors. Proc. Natl. Acad. Sci. USA 74:5463-5467.

52. Schliwa, M. 1984. Mechanisms of intracellular organelle transport, p. 1-82. In J. W. Shay (ed.), Cell and muscle motility: the cytoskeleton. Plenum Publishing Corp.. New York.

53. Scholey, J. M., R. C. Smith, D. Drenckhahn, U. GroschelStewart, and J. Kendrick-Jones. 1982. Thymus myosin. J. Biol. Chem. 257:7737-7745.

54. Schroeder, T. E. 1972. The contractile ring. II. Determining its brief existence, volumetric changes, and vital role in cleaving arbacia eggs. J. Cell Biol. 53:419-434.

55. Schroeder, T. E. 1973. Actin in dividing cells: contractile ring filaments bind heavy meromyosin. Proc. Natl. Acad. Sci. USA 70:1688-1692.

56. Senda, N. 1976. The movement of leucocytes, p. 309-323. In S. V. Perry, A. Margreth, and R. S. Adelstein (ed.), Contractile systems of non-muscle tissues. North-Holland Publishing Co.. Amsterdam.

57. Sivaramakrishnan, M., and M. Burke. 1982. The free heavy chain of vertebrate skeletal myosin subfragment 1 shows full enzymatic activity. J. Biol. Chem. 257:1102-1105.

58. Sobieszek, A., and J. V. Small. 1977. Regulation of the actinmyosin interaction in vertebrate smooth muscle: activation via a myosin light chain kinase and the effect of tropomyosin. J. Mol.
Biol. 112:559-576.

59. Spudich, J. A. 1974. Biochemical and structural studies of actomyosin like proteins from non-muscle cells. J. Biol. Chem. 249:6013-6020.

60. Stossel, T. P., and J. H. Hartwig. 1976. Phagocytosis and the contractile proteins of pulmonary macrophages, p. 529-544. In R. Goldman. T. Pollard. and J. Rosenbaum (ed.). Cell motility. Cold Spring Harbor Laboratory, Cold Spring Harbor, N.Y.

61. Vaillancourt, J. P., C. Lyons, and G. P. Cote. 1988. Identification of two phosphorylated threonines in the tail region of Dictyostelium myosin II. J. Biol. Chem. 263:10082-10087.

62. Varnum, B., and D. R. Soll. 1984. Effects of cAMP on single cell motility. J. Cell Biol. 99:1151-1155.

63. Wagner, P. D., and E. Giniger. 1981. Hydrolysis of ATP and reversible binding to $\mathrm{F}$-actin by myosin heavy chains free of all light chains. Nature (London) 292:560-562

64. Warrick, H. M., A. De Lozanne, L. A. Leinwand, and J. A. Spudich. 1986. Conserved protein domains in a myosin heavy chain gene from Dictyostelium discoidem. Proc. Natl. Acad. Sci. USA 83:9422-9437.

65. Weinberger, C., S. M. Hollenberg, E. S. Ong, J. M. Harmon, S. T. Brower, J. Cidlowski, E. B. Thompson, M. G. Rosenfeld, and R. M. Evans. 1985. Identification of human glucocorticoid receptor cDNA clones by epitope selection. Science 228:740742 .

66. Wessels, D., D. R. Soll, D. A. Knecht, W. F. Loomis, A. De Lozanne, and J. A. Spudich. 1988. Cell motility and chemotaxis in Dictyostelium amoeba lacking myosin heavy chain. Dev. Biol. 128:164-177.

67. Witke, W., W. Nellen, and A. Noegel. 1987. Homologous recombination in the Dictyostelium $\alpha$-actin in gene leads to an altered mRNA and lack of protein. EMBO J. 6:4143-4148.

68. Young, R. A., and R. W. Davis. 1983. Efficient isolation of genes by using antibody probes. Proc. Natl. Acad. Sci. USA 80: 1194-1198.

69. Yumura, S., and Y. Fukui. 1985. Reversible cyclic AMPdependent change in distribution of myosin thick filaments in Dictyostelium. Nature (London) 314:194-196.

70. Yumura, S., H. Mori, and Y. Fukui. 1984. Localization of actin and myosin for the study of ameboid movement in Dictyosteliım using improved immunofluorescence. J. Cell Biol. 99: 894-899. 